\title{
¿Qué es la Humanidad?
}

\section{Dave Elder-Vass}

1 libro 'Debating Humanity' de Daniel Chernilo (2017) es
una defensa desafiante del humanismo, el universalismo y de la necesidad de una sociología filosófica. Es una obra que cuenta con argumentos rigurosos y coherentes, que se confronta a los autores que discute con respeto y ampliamente, y que construye un argumento más vasto y provocativo. La sociología y la filosofía están profundamente interrelacionadas en esta obra, pues los pensadores a los que hace referencia provienen de ambas disciplinas. Cada capítulo trata a profundidad a distintos pensadores cruciales del anterior siglo, de modo tal que usa su trabajo para examinar algún aspecto de aquellos elementos que nos caracterizan como humanos (de forma universal). Si bien para Chernilo la humanidad depende de nuestras propiedades psicológicas e intelectuales (233), su interés se centra en aquellas cualidades que nos hacen seres inherentemente sociales, desde el lenguaje (visto desde Habermas), pasando por la responsabilidad (Jonas), hasta la consideración reflexiva de nuestros planes (Archer). Estas cualidades compartidas no solo definen nuestra humanidad mutua, sino que también nos permiten reflexionar sobre

${ }^{\star}$ Loughborough University. Email: d.elder-vass@lboro.ac.uk

*^Este artículo consiste en la versión en español de la siguiente publicación: Elder-Vass, Dave (2020) 'What is humanity?', Distinktion: Journal of Social Theory, 21(1), pp. 63-66. La traducción se ha realizado por Bernardo Villegas (Pontificia Universidad Católica del Ecuador). La publicación de este artículo se realiza con el amable permiso de Distinktion: Journal of Social Theory, a quienes agradecemos su contribución. 
preguntas acerca de los valores (234) y por tanto nos define como seres morales. 'Estos rasgos antropológicos -dice Chernilo- nos definen como miembros de la misma especie y son la base sobre las cuales emergen las ideas de justicia, identidad, dignidad y buena vida' (1).

Chernilo inicia su libro con la disputa entre Sartre y Heidegger a fines de la década de 1940, con el fin de distinguir entre el humanismo y el antropocentrismo. Allí defiende el principio humanista de que todos los humanos importan (en contra de Heidegger), mientras que rechaza la conclusión de que solo los humanos importan (en contra de Sartre). Ciertamente simpatiza más con Sartre que con Heidegger, y un tema central es su rechazo al argumento heideggeriano que 'ahora es ubicuo en la literatura: culpar al humanismo de la metafísica Occidental por las crisis contemporáneas de la sociedad moderna' (38). La posición de Heidegger, como ilustra Chernilo, es que se encuentra firmemente arraigada en sus circunstancias históricas, y se explica en parte como una estrategia para desviar la atención de su relación con los Nazis. En una perversa inversión de lógica, parecería que Heidegger piensa que puede culpar al humanismo de la deshumanización que los nazis provocaron a las personas que enviaron a los campos de concentración y las cámaras de gas (46-50).

De forma sucinta, Chernilo conecta esta posición a los debates sobre el posthumanismo, en el cual a veces se adopta la posición influenciada por Heidegger (como en el trabajo de Braidotti) de que el humanismo 'no es sino una violenta y excluyente macro-ideología del Occidente que encarna todo lo que está mal con la Modernidad'(14). Su discusión sobre el posthumanismo es breve, lamentablemente, pero aún así aclara que, en la práctica, esta corriente emplea cierto tipo de humanismo - el mismo que Chernilo propone- para construir la crítica a lo que conciben como 
humanismo, a saber, 'la ideología intrínsecamente racista, violenta y excluyente de los hombres blancos, adultos, heterosexuales y burgueses que la han impuesto violentamente en todo el mundo' (15). Me hubiera gustado ver que este acercamiento crítico con el posthumanismo se hubiera realizado con un enfoque más sustancial en el libro, pero quizás es algo que tratará en un trabajo futuro. Hay múltiples vías de investigación productivas que se pueden desarrollar en este punto. Notablemente, se podría problematizar el argumento de que el humanismo es ideológicamente poderoso precisamente porque hace eco del sentido de quiénes y qué es lo que somos, y también las demandas humanistas han sido empleadas repetidamente para disimular y justificar ciertas políticas y estructuras anti-humanistas, como el patriarcado o el esclavismo hasta el racismo moderno que excluye a quienes atacan de la categoría de lo humano. En este caso, el problema no es un humanismo universalista, sino la apropiación errónea de la retórica del humanismo para legitimar la opresión, la cual usualmente está fundamentada por una retórica que solamente se refiere a quienes son los que enteramente cuentan como humanos. En la medida en que las críticas de 'humanismos' excluyentes sean acciones para incluir a más personas dentro de la categoría de quienes merecen protección moral, este tipo de críticas son humanismos en sí mismas, a pesar de negarlo. Al hacerlo precisamente minan su coherencia moral.

Se podría esperar que un sociólogo se oponga a la idea de que el humanismo es inseparable de la retórica de quien cuenta, pero lo que está construyendo Chernilo -lo que él llama una antropología filosófica- es una especie de ontología del humano, una enumeración de las cualidades que nos hacen lo que somos. Una ontología de este estilo nos permitiría separar con mayor aptitud lo humano de lo no-humano, de una manera que no dependa en retóricas endebles y sesgadas. Una manera de hacerlo sería 
observar las estructuras físicas y las propiedades que son característicamente humanas, y usarlas para delinear nuestra humanidad; pero para Chernilo y, según lo sospecho, para sus lectores, son nuestras capacidades sociales e intelectuales las que nos hacen distintivamente humanos, distintivamente morales y merecedores de protección moral. Esas capacidades podrían yacer en nuestras estructuras y propiedades físicas, pero son emergentes a partir de ellos - así como también son emergentes del modo en las cuales las estructuras sociales más amplias de las que somos parte influencian el tipo de seres que somos. Como Chernilo afirma, 'la centralidad sociológica del problema la estructura y la agencia se mantiene por el hecho de que es, en sí misma, constitutiva de la condición humana' (182). Los humanos de cualquier humanismo plausible son seres envueltos en ,y moldeados por, las estructuras y vida sociales.

Esta discusión sobre la estructura y la agencia pone a Chernilo en contacto con la ontología social, tal como lo hacen los realistas críticos y al igual que una amplia gama de tendencias filosóficas de las ciencias sociales - académicos que se encuentran de hecho conduciendo a propósito una sociología filosófica, incluso aunque lo hagan de una manera distinta. Esto pone en cuestión la relación entre la antropología filosófica y estas otras tradiciones, en particular sobre la pregunta de si la antropología filosófica es una forma de ontología social, o si se encuentra en conflicto con esta última o, finalmente, si simplemente es una forma potencialmente diferente y complementaria de ontología social. Quizás la respuesta a esta pregunta podría variar para diferentes versiones de antropología filosófica, pero desde mi punto de vista, la antropología filosófica de Chernilo es una forma de ontología social - aunque una que mueve productivamente nuestra atención más allá de las preguntas usuales consideradas por quienes realizan ontología social. Él se interroga acerca de cuáles son las capacidades 
distintivas de los humanos, y brinda una rica revisión de ellas que reconoce que estas capacidades están fundadas en la materialidad de nuestros cuerpos y cerebros, pero que también están moldeadas por nuestras interacciones con el mundo social. Podría argumentar que algunas de estas capacidades, en términos causales, son realmente capacidades de estructuras sociales más amplias, que se implementan y despliegan mediante los seres humanos, que figuran como partes en relación con un todo, aunque siempre son dependientes de la acción continua y contingente de los humanos y, por ende, de sus elecciones reflexivas. El lenguaje, por ejemplo, es en el fondo un producto de grupos sociales más amplios, los cuales he denominado círculos lingüísticos, a pesar de que la consecuencia es que estos grupos confieren una capacidad aumentada para comunicarse a sus miembros (Elder-Vass, 2012, pp. 100-120).Chernilo se enfoca, de todos modos, no en la causalidad sino en la ética (188) y esto configura los elementos de la ontología de lo humano que él considera y el modo de analizarlos

Este paso desde la ontología -o antropología filosófica- hacia la ética se desarrolla, de todos modos, con cierta dificultad (Elder-Vass, 2010). Consideremos su discusión del trabajo de Boltanski sobre el aborto. Chernilo cita con aprobación el deseo de Boltanski de abandonar el debate sobre el inicio de la vida humana a favor de preguntas más fundamentales sobre ¿qué es y cómo reconocemos socialmente una vida que es de hecho humana?' (207). Pero en este punto las arenas movedizas morales se empiezan a sentir. ¿Es el argumento que los fetos no son todavía humanos, pues carecen de capacidades sociales que se requieren para serlo, y por lo tanto podrían ser abortados sin reparos? De ser así, ¿qué es lo que previene que extender este argumento hacia otros que no son capaces de participar plenamente en la socialidad humana? ¿O es el caso de que son capaces de convertirse en humanas y, por lo tanto, el aborto no sería aceptable? Sabiamente, quizás, ni 
Boltanski, ni Chernilo, aunque han puesto de relieve esta pregunta, brindan una respuesta clara y concisa (219-220).

El problema, como sugiero, es que los complejos problemas morales no pueden resolverse a través de la aplicación de un principio único a un objeto de interés - por ejemplo, el caso del feto. Todos los problemas morales contemporáneos importantes demandan de nuestra parte que ponderemos múltiples consideraciones, y en este caso se trata del balance más obvio entre las necesidades y los derechos morales del feto, por un lado, y las necesidades y los derechos morales de la mujer que lo lleva dentro de sí. Las soluciones legales basadas desde el momento de la concepción pueden aparecer como arbitrarias, pero son una solución práctica a la necesidad de encontrar este balance, y la cuestión sobre cuándo una vida 'es efectivamente una vida humana' no provee una ruta alternativa éticamente viable. Una ética basada en el reconocimiento del valor moral de todos los humanos es un punto de partida para un debate ético real, el cual siempre debe ponderar entre las necesidades y los derechos de diferentes humanos (y, a su vez, nohumanos, una vez que rechazamos el antropocentrismo). A veces puede ser una consideración decisiva, pero no pueden haber supuestos a priori, de que así lo sean.

Pero es positivo que Chernilo concibaa estas preguntas como pertenecientes a la sociología, y conciba a la sociología crítica como una rama que orienta su atención explícitamente hacia nuestros valores y sus raíces. Él inserta la filosofía dentro de la sociología, con el fin de aunar la sociología con lo normativo. La de Chernilo no es una la criptonormatividad, tal como es criticada por Sayer: "buena parte [de la ciencia social crítica] solamente brinda al lector un sentimiento vago y negativo sobre los fenómenos que se están analizando, pero no intenta mencionar en qué sentido en particular y por qué razones esto es problemático" (Sayer, 2011, 
p.229). Esto se vuelve particularmente claro en Chernilo en su discusión sobre la crítica de Boltanski a Bourdieu. Este último autor, de acuerdo con Boltanski y otros críticos, cree que los científicos sociales son capaces de criticar normativamente, mientras niegan que los actores ordinarios tengan las 'competencias antropológicas' que hacen esto posible (225). El trabajo de Boltanski se orienta en la dirección contraria: los actores ordinarios son capaces de juzgar y criticar, y el trabajo de los científicos sociales es describir y analizar cómo lo hacen - ¡pero no ejercer una crítica normativa por ellos mismos! (227). Para una realista humanista (como Chernilo o yo), en contraste, tanto los actores ordinarios como los científicos sociales son seres humanos con el mismo conjunto de competencias antropológicas. Ambos son capaces de criticar, y ambos tienen el dereco y la facultad de formular argumentos normativos. Si los sociólogos realizan efectivamente argumentos normativos, tienen la responsabilidad de explicar las bases en las que se fundamentan sus argumentos: por ello la necesidad de una sociología filosófica.

En cierto sentido, Debating Humanity es una forma de lo que Bhaskar llama crítica inmanente (Bhaskar, 1975), pues sugiere enfáticamente que incluso cuando los sociólogos rechazan el humanismo, su trabajo depende tratar a los humanos como entidades que comparten muchas de las capacidades antropológicas que ellos enumeran (184-5). El anti-humanismo sociológico, de ser cierto, es incoherente, y de este modo la pregunta no es ¿¿humanista o anti-humanista?’, sino más bien ‘qué tipo de humanista?' y ‘hacia dónde nos lleva ese humanismo?'. 


\section{Referencias}

Bhaskar, R. (1975). A realist theory of science (1st ed.). Leeds: Leeds Books.

Chernilo, D. (2017). Debating Humanity: Towards a Philosophical Sociology. Cambridge University Press.

Elder-Vass, D. (2010). Realist critique without ethical naturalism or moral realism. Journal of Critical Realism, 9(1), 33-58.

Elder-Vass, D. (2012). The Reality of Social Construction. Cambridge: Cambridge UP.

Sayer, A. (2011). Why things matter to people. Cambridge: Cambridge UP. 